\title{
A case of orbital cellulitis and pan-ophthalmitis in dengue haemorrhagic fever in a child
}

\author{
Priyanthi Molligoda ${ }^{1}$, Prathik Sen ${ }^{2}$ \\ Sri Lanka Journal of Child Health, 2006; 35: 38-40
}

(Key words: orbital cellulitis, pan-ophthalmitis, dengue haemorrhagic fever, child)

\section{Case report}

An eight year old girl with Down syndrome was admitted in our hospital on $11^{\text {th }}$ August 2005 with a serologically confirmed dengue haemorrhagic fever (Grade 2) and gross swelling and pain of left eye of 4 days duration.

She was admitted to another hospital 5 days previously with a 2 day history of high fever with vomiting. She was noted to be febrile \& flushed in the face. There had been no obvious swelling or pain in and around the eyes at the time. The child was relatively well. Her blood pressure was $120 / 70 \mathrm{~mm}$ $\mathrm{Hg}$, hard palate petechiae were present and the Hess test was strongly positive. White cell count on admission to that hospital was $1.71 \times 10^{9} / \mathrm{L}$, (N42\%, L58\%). Minimum platelet count was $17 \times 10^{9} / \mathrm{L}$. The haematocrit was $42 \%$, haemoglobin $14.5 \mathrm{~g} / \mathrm{dl}$, SGOT $114 \mathrm{IU} / \mathrm{L}$ and SGPT $67 \mathrm{IU} / \mathrm{L}$. The dengue fever IgM antibody was positive whilst IgG was negative. She had been treated with intravenous fluids and platelet concentrate. After three days, her left eyelids and eye were noted to be swollen and red. A diagnosis of orbital cellulites and pan-ophthalmitis was made and intravenous high-dose antibiotics were started.

At the time of admission to our hospital four days later, there was gross swelling and proptosis of left eye (Figure 1). The white cell count had increased to $16.7 \times 10^{9} / \mathrm{L}$ with neutrophil leucocytosis. The platelet count was $105 \times 10^{9} / \mathrm{L}$ and the haematocrit 40.9 . The MRI brain scan revealed left orbital swelling with loss of normal anatomy of the left globe (Figure 2). The right orbit was normal.

Inflammatory changes of right maxillary sinus were noted (Figure 3). The cavernous sinus was normal.

$\begin{array}{lrr}{ }^{1} \text { Consultant } & \text { Paediatrician, } & { }^{2} \text { Consultant } \\ \text { Opthalmologist, Apollo Hospitals, } & \text { Colombo }\end{array}$

(Received on 16 August 2005. Accepted 20 October 2005)
Since the eye was unsalvageable, it was eviscerated under general anaesthesia. Bacillus species were isolated from the eviscerated eye. The child made a good recovery following the operation and had a total of 7 days of intravenous antibiotics.

\section{Discussion}

Orbital cellulitis in children following paranasal sinusitis is a well known entity ${ }^{1,2}$. This child had occult maxillary sinusitis when she developed dengue haemorrhagic fever. It was unfortunate that she also had Down syndrome which has a predilection for upper respiratory infections.

It is well known that dengue haemorrhagic fever is associated with leucopenia, neutropenia and relative lymphocytosis ${ }^{3,4}$. This particular child had severe neutropenia which predisposed to secondary bacterial infection. It is most likely that the infection of the eye and the orbital cellulitis was a result of blood borne spread from the maxillary sinus during this neutropenic state.

We could not find any similar cases reported in the medical literature. We believe it is important to be aware of this particular complication, with a view to prevent it. We feel that there is a place for broad spectrum prophylactic antibiotics even in confirmed cases of dengue fever when there is severe febrile neutropenia (absolute neutrophil count $<1 \times 10^{9} / \mathrm{L}$ ).

\section{Acknowledgements}

We are grateful to the child and her parents who consented to publish this case and to Dr R Prasad, Consultant Radiologist, Apollo Hospitals Colombo for his valuable assistance with the MRI.

\section{References}

1. Sebol et al Orbital complications of sinusitis in children. Otolaryngeal 2002; 31 (3): 131-6. 
2. McCarty et al. Manifestations of fungal cellulitis of the orbit in children with neutropenia \& fever. Ophthal Plast Reconst Surgery 2004; 20 (3): 217-23.

3. Robert V Gibbons. Dengue: an escalating problem. British Medical Journal 2002; 324:1563-6.
4. World Health Organization. Dengue haemorrhagic fever: diagnosis, treatment, prevention and control, $2^{\text {nd }}$ ed, Geneva: WHO 1997.

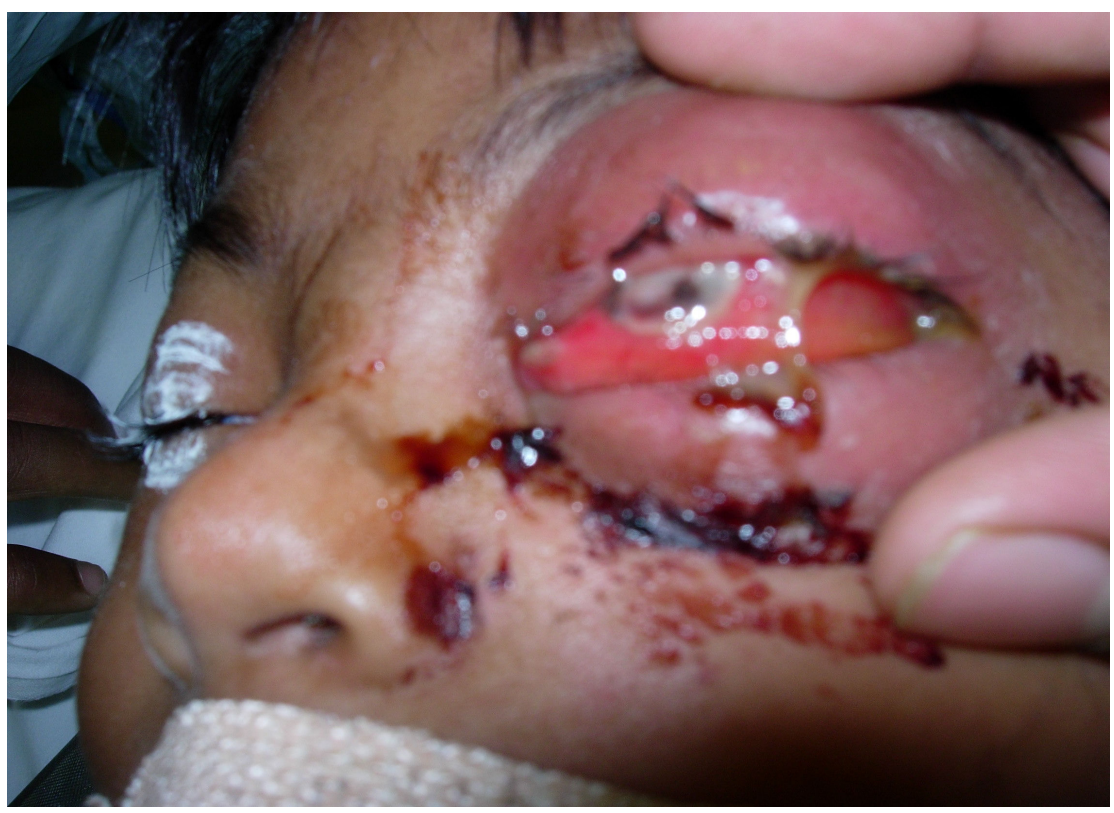

Figure 1 Swollen orbit showing the perforation of the cornea

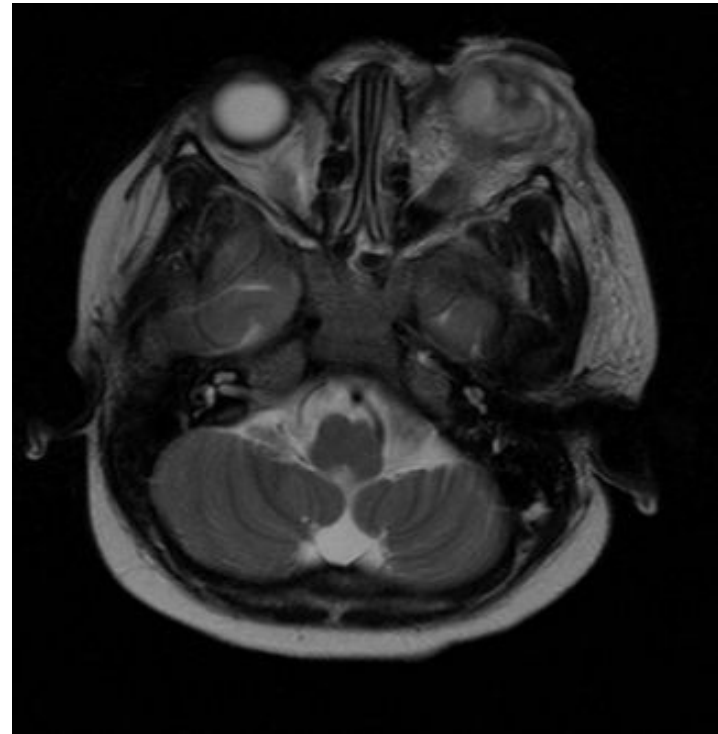

Figure 2 Proptosis and swelling of left eye

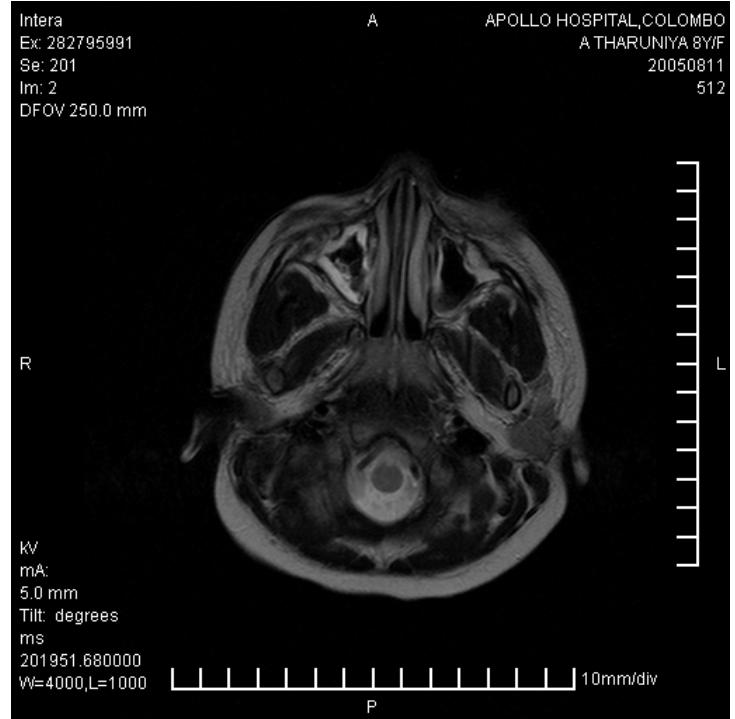

Figure 3 Arrow shows mucosal thickening of right maxillary sinus 
